\title{
Real time PCR quantification of frataxin mRNA in the peripheral blood leucocytes of Friedreich ataxia patients and carriers
}

\author{
L Pianese, M Turano, M S Lo Casale, I De Biase, M Giacchetti, A Monticelli, C Criscuolo, A Filla, \\ S Cocozza
}

The most common causative mutation of Friedreich ataxia (FRDA) is the unstable hyperexpansion of an intronic GAA triplet repeat that impairs frataxin transcription. Using real time quantitative PCR, we showed that FRDA patients had residual levels of frataxin mRNA ranging between $13 \%$ and $30 \%$ and that FRDA carriers had about $40 \%$ of that of controls. Asymptomatic carriers also showed reduced frataxin mRNA levels. We found an inverse correlation between the number of GAA repeats and frataxin mRNA levels. Real-time quantitative PCR may represent an alternative assay for FRDA molecular diagnosis.

F riedreich ataxia (FRDA) is an autosomal recessive progressive neurodegenerative disorder. ${ }^{1}$ The disease presents with gait and limb ataxia with onset usually in the first two decades of life, but later forms have also been described. $^{2}$ Extra neurological features include skeletal deformity, left ventricular hypertrophy, and diabetes. ${ }^{1}$

GAA repeat expansion within the first intron of the X25 gene is the most common mutation in FRDA and it is present in $98 \%$ of the disease alleles. ${ }^{3}$ Few patients are compound heterozygotes for a GAA expansion and a point mutation ${ }^{4}$ and no patient homozygous for point mutation has been described. A correlation was shown between GAA expansion size and the severity of disease. ${ }^{56}$ The gene $X 25$ encodes a mitochondrial protein named frataxin, ${ }^{3}$ which seems to be involved in mitochondrial iron homeostasis. ${ }^{7}$ Expanded GAA tracts lead, at the transcriptional level, to a reduction of X25 mRNA that is related to the size of the expansion. ${ }^{89}$

Up to now, traditional assays such as semi-quantitative PCR, RNase protection, and Western blot were used to investigate X25 mRNA and frataxin levels in FRDA patients and FRDA carriers. ${ }^{3} 81011$ In this study, real time quantitative polymerase chain reaction (PCR), a highly sensitive and specific method, was used for the first time to evaluate frataxin mRNA expression in peripheral blood leucocytes from FRDA patients and FRDA carriers.

\section{METHODS}

Peripheral blood samples were collected, following written informed consent, from 10 FRDA patients (two male and eight female), homozygous for GAA repeat expansion and three FRDA carriers heterozygous for GAA expansion.

GAA molecular analysis was performed as previously described. ${ }^{5}$ Total RNA was extracted from $2.5 \mathrm{ml}$ peripheral blood leucocytes using the PAXgene Blood RNA Kit (Qiagen, Valencia, CA, USA).

Total RNA ( $1 \mu \mathrm{g})$ was reverse transcribed with $100 \mathrm{U}$ of Superscript II RNase H- Reverse Transcriptase (Invitrogen,

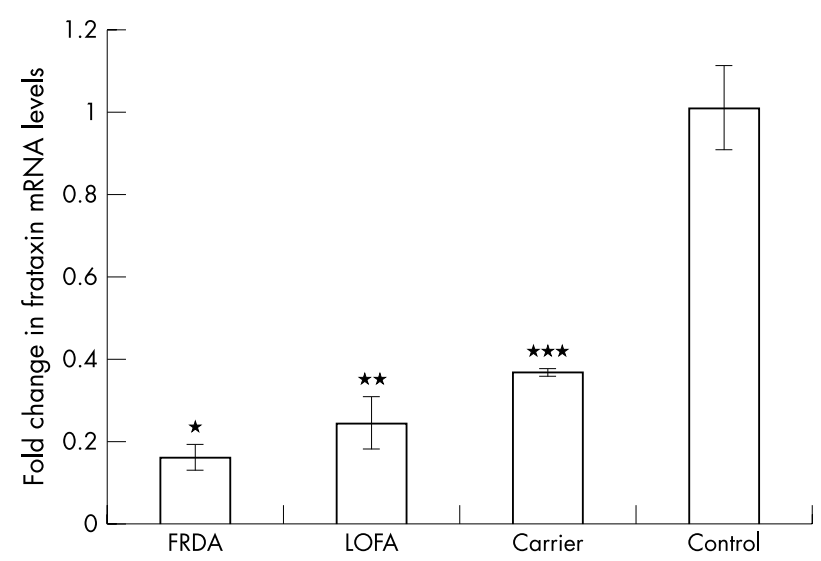

Figure 1 Quantitative gene expression of frataxin using real time PCR with relative quantification analysis using REST (relative expression software tool). Fold change (y axis) represents the relative expression of the frataxin mRNA in comparison to the control group (equals 1 by definition) normalised by HPRT1 reference gene expression. Data are mean (SE); ${ }^{*} p=0.001,{ }^{* *} p=0.022,{ }^{* * *} p=0.016$.

Gaithersburg, MD, USA) according to the manufacturer's instructions. A $1 \mu \mathrm{l}$ sample of cDNA was amplified by real time PCR using PCR primers and TaqMan MGB probes for Friedreich ataxia (FRDA) and hypoxanthine phosphoribosyltransferase 1 (HPRT1) genes as reference gene (Perkin-Elmer Applied Biosystems (PE-ABI), Foster City, CA, USA). Each sample was run in triplicate for both FRDA and HPRTl in $20 \mu$ reaction using TaqMan Universal PCR Master Mix according to the manufacturer's instructions (PE-ABI). Reactions were performed in an ABIPrism 7000 sequence detector system (PE-ABI).

Quantitative real time PCR analysis was carried out using the $2(-$ Delta Delta $C(T))$ method $\left(2^{-\Delta \Delta \mathrm{Ct}}\right) \cdot{ }^{12}$ The new relative expression software tool (REST) was used to calculate the relative expression ratios on the basis of group means for target frataxin transcript versus reference HPRTl transcript. ${ }^{13}$ REST also tests the group ratio results for significance by a randomisation test. ${ }^{13}$

Correlations analyses were performed by using the SPSS statistical software package.

\section{RESULTS}

To investigate frataxin mRNA expression, 10 FRDA patients, three FRDA carriers, and three controls were analysed. Five patients had typical FRDA with onset within the first 20 years

Abbreviations: FRDA, Friedreich ataxia; HPRT1, hypoxanthine phosphoribosyltransferase 1; PCR, polymerase chain reaction 

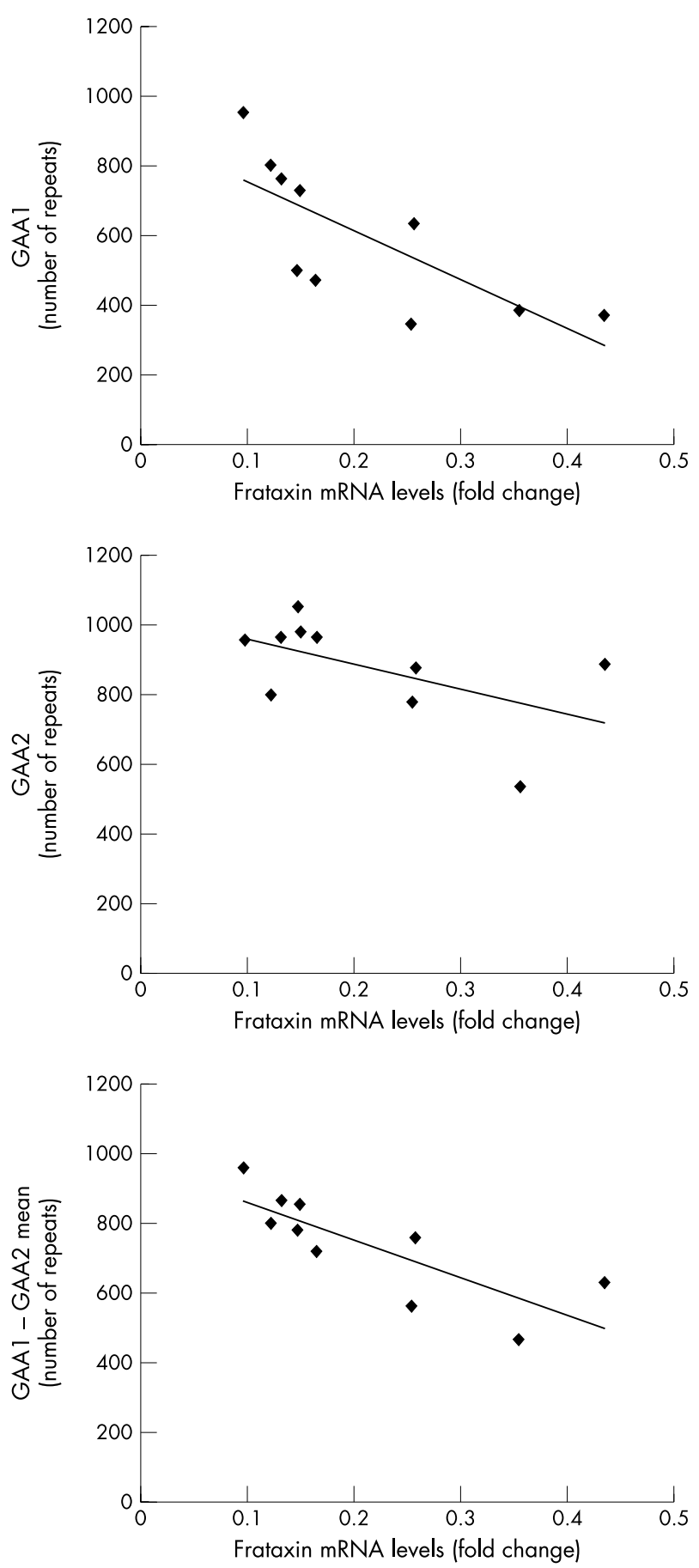

Figure 2 Correlation between frataxin mRNA levels, expressed as fold change, and repeat numbers of GAA1 (top), GAA2 (middle) and GAA1-GAA2 mean (bottom) in 10 FRDA patients.

of life and five had onset after 20 years of age (late-onset FRDA, LOFA). ${ }^{2}$ The mean (SD) length of the expanded alleles was 741 (229) repeats with range of 348-1057. Mean (SD) age at onset was $12.6(5.4)$ years in typical patients and 21.0 (0.7) years in LOFA patients.

Using quantitative real time PCR we found that frataxin mRNA was down-regulated in typical FRDA patients in comparison to the control group by a factor of 6.04 $(p=0.001)$. We also found that frataxin was significantly down-regulated in LOFA patients by a factor of 4.65 $(\mathrm{p}=0.022)$ and in FRDA carriers by a factor of 2.84 $(p=0.016)$ in comparison to the control group (fig 1$)$. In summary, all FRDA patients (typical and LOFA) showed frataxin mRNA levels ranging from $13 \%$ to $30 \%$ of that of the healthy individuals, with carriers having about $40 \%$ of normal levels.

Furthermore, we evaluated the relationship between frataxin mRNA levels and GAA repeat size. The smaller and the larger in each pair of alleles were indicated as GAAl and GAA2, respectively. We found a strong inverse correlation between frataxin mRNA levels and number of repeats. In particular the following correlations were obtained: for GAA mean, $\mathrm{r}^{2}=-0.80$; for GAAl, $\mathrm{r}^{2}=-0.74$; and for GAA2, $r^{2}=-0.55$ (fig 2).

\section{DISCUSSION}

The present study is the first to use real time PCR to evaluate frataxin mRNA expression in FRDA patients and carriers. Real-time PCR is the most sensitive method for the detection and quantification of gene expression levels. Using real time PCR we found that all FRDA patients (typical and LOFA) showed frataxin mRNA levels ranging from $13 \%$ to $30 \%$ of that of healthy individuals. Furthermore, we were able to detect differences in frataxin mRNA levels between LOFA and typical patients. Previous studies used less sensitive methods such as semi-quantitative PCR, RNase protection, and Western blot to identify reductions in the amount of X25 mRNA and frataxin protein in FRDA patients. ${ }^{3}{ }^{10}{ }^{11}$ In these studies the residual amount of frataxin varied between $4 \%$ and $29 \%$ of the level in normal controls. ${ }^{11}$ Our data are in accordance with these previously reported data.

Here we report, for the first time, accurate quantification of frataxin mRNA in healthy FRDA carriers. These individuals showed about $40 \%$ of the normal frataxin mRNA levels. It is intriguing that these levels are not so different from that found in LOFA patients. It should be emphasised that, however, no overlap between the two groups was observed.

In addition, we found a significant inverse correlation between frataxin mRNA levels and GAA repeat number. The best correlation was found for GAA mean $\left(\mathrm{r}^{2}=-0.80\right)$ and for GAAl $\left(r^{2}=-0.74\right)$. A correlation was previously reported between the residual frataxin protein level and the size of GAAl. ${ }^{11}$ Considering the technical difficulties in Friedreich ataxia molecular diagnosis by PCR on genomic DNA due to the long GAA repeat, our data suggest that real time quantitative PCR could represent an alternative assay for Friedreich ataxia molecular diagnosis.

\section{Authors' affiliations}

L Pianese, M Turano, M S Lo Casale, BioGeM Consortium, c/o Department of Molecular and Cellular Biology and Pathology, Frederico II University, Naples, Italy

L Pianese, M Turano, M S Lo Casale, I De Biase, M Giacchetti, A Monticelli, S Cocozza, Department of Molecular and Cellular Biology and Pathology and IEOS, CNR, Federico II University, Naples, Italy C Criscuolo, A Filla, Department of Neurology, Federico II University, Naples, Italy

This work was supported in part by a grant from BioGeM Consortium. Competing interests: none declared

Correspondence to: $\mathrm{Dr}$ L Pianese, BioGeM Consortium, c/o Dipartimento di Biologia e Patologia Cellulare e Molecolare, Università "Federico II", Via S. Pansini, 5, 80131 Napoli, Italy; pianese@biogem.it

Received 18 September 2003

In revised form 12 November 2003

Accepted 12 November 2003

\section{REFERENCES}

1 Harding AE. Classification of the hereditary ataxias and paraplegias. Lancet 1983; 1:1151-5. 
2 De Michele G, Filla A, Cavalcanti F, et al. Late onset Friedreich's disease: clinical features and mapping of mutation to the FRDA locus. J Neurol Neurosurg Psychiatry 1994;57:977-9.

3 Campuzano V, Montermini L, Moltò MD, et al. Friedreich's ataxia: autosomal recessive disease caused by an intronic GAA triplet repeat expansion. Science 1996;271:1423-7.

4 Cossee M, Durr A, Schmitt M, et al. Friedreich's ataxia: point mutations and clinical presentation of compound heterozygotes. Ann Neurol 1999:45:200-6.

5 Filla A, De Michele G, Cavalcanti F, et al. The relationship between trinucleotide (GAA) repeat length and clinical features in Friedreich's ataxia. Am J Hum Genet 1996;59:554-60.

6 Mateo I, Llorca J, Volpini V, et al. GAA expansion size and age at onset of Friedreich's ataxia. Neurology 2003;61:274-5.

7 Koutnikova H, Campunzano V, Foury F, et al. Studies of human, mouse and yeast homologues indicate a mitochondrial function for frataxin. Nat Genet 1997;16:345-51.
8 Bidichandani SI, Ashizawa T, Patel PI. The GAA triplet repeat expansion in Friedreich ataxia interferes with transcription and may be associated with an unusual DNA structure. Am J Hum Genet 1998;62:111-21.

9 Ohshima K, Montermini L, Wells RD, et al. Inhibitory affects of expanded GAA TCC triplet repeats from intron 1 of the Friedreich ataxia gene on transcription and replication in vivo. J Biol Chem 1998;273:14588-95.

10 Cossee M, Campuzano V, Koutnikova H, et al. Frataxin fracas. Nat Genet 1997;15:337-8.

11 Campuzano V, Montermini L, Lutz Y, et al. Frataxin is reduced in Friedreich ataxia patients and is associated with mitochondrial membranes. Hum Mol Genet 1997;6:1771-80.

12 Livak KJ, Schmittgen TD. Analysis of relative gene expression data using realtime quantitative PCR and the 2(-Delta Delta C(T)) method. Methods $2001 ; 25: 402-8$.

13 Pfaffl MW, Horgan GW, Dempfle L. Relative expression software tool (REST) for group-wise comparison and statistical analysis of relative expression results in real-time PCR. Nucleic Acids Res 2002;30:e36

\section{HISTORICAL NOTE}

\section{Lewis Carroll's Humpty Dumpty: an early report of prosopagnosia?}

$\mathrm{P}$ rosopagnosia is a rare form of visual agnosia characterised by impaired recognition of familiar faces (or equivalent stimuli). The term was coined by Bodamer in 1947, although the phenomenon had been described towards the end of the 19th century by Quaglino (1867), Hughlings Jackson (1872, 1876), and Charcot (1883). ${ }^{12}$ Brief accounts thought to be suggestive of prosopagnosia have been identified in writings from classical antiquity by Thucydides and Seneca. ${ }^{3}$ While there are dangers in this type of retrospective case identification, nonetheless I venture to suggest another early description of prosopagnosia.

The account is taken from Through the looking-glass and what Alice found there (1872) by Lewis Carroll (pseudonym of the Reverend Charles Lutwidge Dodgson). In chapter 6, Alice notices that the egg that she has just purchased

\section{had eyes and a nose and mouth; and when she had come close to it, she saw clearly that it was HUMPTY DUMPTY himself. "It can't be anybody else!" she said to herself. "I'm as certain of it, as if his name were written all over his face."}

Discussion follows, in which Humpty Dumpty, sitting precariously balanced upon a wall, gives his famous definition of the meaning of a word ("just what I choose it to mean") and coins the term "portmanteau word". As Alice takes her leave of Humpty Dumpty, the subject of facial recognition recurs, in the following exchange:

\footnotetext{
"Good-bye, till we meet again!" she said as cheerfully as she could.

"I shouldn't know you again if we did meet," Humpty Dumpty replied in a discontented tone, giving her one of his fingers to shake: "you're so exactly like other people." "The face is what one goes by, generally," Alice remarked in a thoughtful tone.

"That's just what I complain of," said Humpty Dumpty. "Your face is the same as everybody else has-the two eyes, so-" (marking their places in the air with his thumb) "nose in the middle, mouth under. It's always the same. Now if you had the two eyes on the same side of the nose, for instanceor the mouth at the top-that would be some help."

"It wouldn't look nice," Alice objected.
}

Humpty Dumpty reports an inability to recognise a familiar face, yet is able to recognise eyes, nose, and mouth and their correct positions, as is also the case with prosopagnosics. In developmental or congenital prosopagnosia, where the neuropsychological deficit is perhaps most pure because acquired cases following pathological insults such as cerebrovascular disease may not respect functional boundaries and may be accompanied by additional neurological signs such as visual field defects, there are impairments in face identity matching tasks but the ability to identify sex, age, emotional facial expression, and eye gaze direction is preserved. ${ }^{45}$ As in these cases, Humpty Dumpty's account seems to indicate preserved componential but impaired configural processing. There is also a suggestion that Humpty Dumpty might be able to use extraneous information to assist in facial recognition, his example being two eyes on one side of the nose or the mouth at the top of the face. Prosopagnosics may use extraneous visual cues such as spectacles, facial jewellery, and hair colour or style to aid facial recognition..$^{3-5}$

Whether Dodgson wrote this passage purely from imagination, or he based it upon observation of a prosopagnosic individual is not known. He did occasionally parody human idiosyncrasies, for example he himself appears as the Dodo because of his stammer ("Do-do-Dodgson") in Alice's Adventures in Wonderland (1865, chapters 2 and 3).

\section{A J Larner}

Cognitive Function Clinic, Walton Centre for Neurology and Neurosurgery, Lower Lane, Fazakerley, Liverpool, L9 7Ј, UK; a.larner@thewaltoncentre.nhs.uk

\section{References}

1 Pryse-Phillips W. Companion to clinical neurology. 2nd edn. Oxford: Oxford University Press, 2003:783.

2 Della Sala S, Young AW. Quaglino's 1867 case of prosopagnosia. Cortex 2003;39:533-40

3 De Haan EHF. Covert recognition and anosognosia in prosopagnosic patients. In: Humphreys GW, ed. Case studies in the neuropsychology of vision. Hove: Psychology Press, 1999:161-80.

4 Nunn JA, Postma P, Pearson R. Developmental prosopagnosia: should it be taken at face value? Neurocase 2001;7:15-27.

5 Larner AJ, Downes JJ, Hanley JR, et al. Developmental prosopagnosia: a clinical and neuropsychological study [Abstract P591]. J Neurol 2003;250(suppl 2):11156. 